
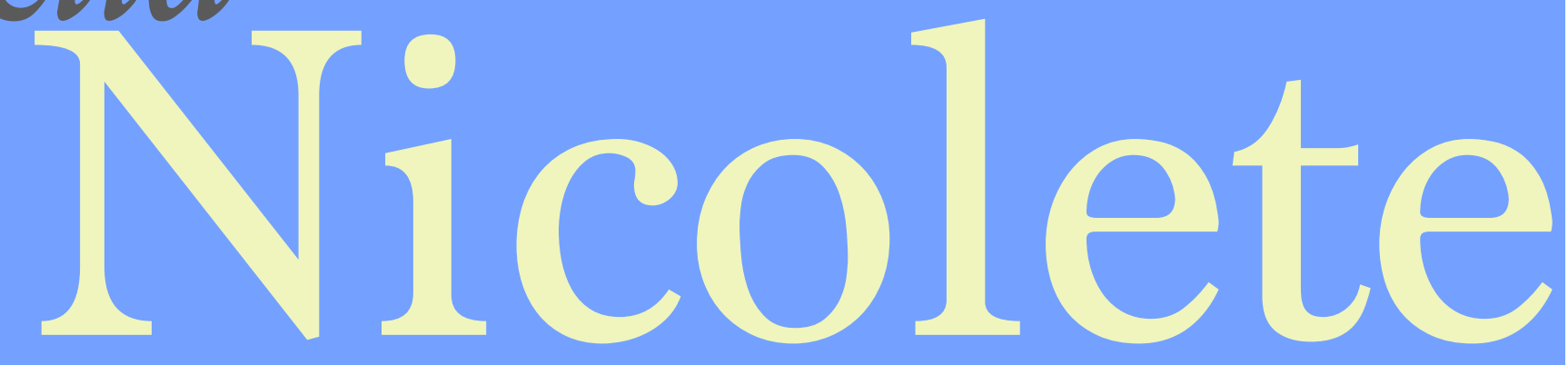

\title{
As dinâmicas coletivas de criação em teatro e os diferentes sentidos de dramaturgia
}

Resumo: Analisadas a criação coletiva e o processo colaborativo, verifica-se que, dentre as características das encenações resultantes, encontram-se configurações formais que escapam à estrutura dramática convencional e seu funcionamento orgânico. Pretende-se, com este artigo, refletir sobre alguns sentidos abarcados pelo termo dramaturgia no teatro contemporâneo a fim de fundamentar a busca pelas novas formas do texto verbal e da cena criadas em dinâmicas coletivas.

Palavras-chave: Dramaturgia; Teatro; Processo Colaborativo; Rapsódia; Dramaturgismo 


\section{As Dinâmicas Coletixas de Criação em Teatro e os Diferentes Sentidos de Dramaturgia}

\section{ADÉLIA NICOLETE ${ }^{1}$}

As dinâmicas coletivas em arte têm se mostrado, a partir dos anos 1950, um potente meio de criação. Muitas delas emergiram no caudal da contracultura e de seus pressupostos de desierarquização de funções, de autonomia em relação aos mecanismos consagrados de produção, de subversão à cultura dominante e seu culto à figura de um autor único que, muitas vezes, sobrepunha-se à obra.

Há quem considere redundância falar em dinâmicas coletivas quando se trata de teatro - arte grupal por natureza, a construção da cena já implicaria em colaboração mútua. Ocorre, porém, que os esquemas convencionais de produção operam com atribuição específica de funções, que não se inter-relacionam e costumam obedecer a uma hierarquia. No topo da pirâmide está o diretor a coordenar atores, iluminadores, cenógrafos, figurinistas, músicos, cenotécnicos, divulgadores, que respondem às suas concepções de modo paralelo. É comum que apenas o encenador tenha uma visão geral do trabalho até bem próximo da estreia, quando todas as áreas são agregadas, constituindo o todo da encenação. Esse modelo difere substancialmente de práticas como a criação coletiva ou o processo colaborativo.

\footnotetext{
${ }^{1}$ Mestre e Doutora em Teatro pela ECA-USP. Email: adelianicolete@gmail.com
} 
A criação coletiva foi um dos primeiros movimentos rumo à equivalência criativa e à divisão de responsabilidades que confluem para a construção do espetáculo. No Brasil, ela desenvolveu-se e alcançou proporções significativas a partir de meados dos anos 1960, mantendo-se por quase duas décadas como importante procedimento de pesquisa estética e de militância, bem como de formação e fortalecimento do teatro de grupo. Na década de 1990, ganharam força no país os coletivos de artes visuais, música e cinema. Eles apresentaram uma saída para a viabilização, divulgação e comercialização de trabalhos fora da tirania do mercado. Nesse contexto, despontou o processo colaborativo que, desde então, tem sido utilizado por um número cada vez maior de grupos teatrais.

Herdeira de alguns princípios da criação coletiva, a dinâmica colaborativa pressupõe que as hierarquias sejam substituídas pelas responsabilidades criativas, não havendo predomínio do autor, do diretor ou dos intérpretes. Há proposições a serem feitas por todos os envolvidos e funções a serem desempenhadas, sempre com interferência mútua entre os criadores, mas com decisões e assinatura final de cada área, sob a coordenação geral da direção (ABREU, 2003). A dramaturgia desenvolve-se no decorrer do processo, com base nas pesquisas, na improvisação dos atores, no ir e vir das proposições, experimentações e avaliações de cenas (SILVA, 2011). O grupo pode abrir os ensaios ao público e ter também sua colaboração, na forma de análises, críticas e sugestões. Novas etapas de criação sucedem-se até que chegue o momento das finalizações de cada área e da busca de uma identidade geral do trabalho. Dificilmente um espetáculo nesses moldes pode se considerar finalizado, pois é permanentemente revisto em função da relação com o espectador, da 
rotatividade dos intérpretes ou dos diferentes espaços de exibição (NICOLETE, 2005).

Constata-se que, assim como na criação coletiva, a dramaturgia baseada em múltiplas proposições, tende a uma conformação igualmente polifônica. Diferente de um autor individual, no controle do texto desde as primeiras ideias até a conformação final, o dramaturgo em processo avança no mesmo passo da cena, a administrar criativamente as sugestões. Seu objetivo não é uniformizar as colaborações, nem reduzi-las a um denominador comum, ao contrário, é compor um trabalho com os diferentes materiais - situações improvisadas, textos sugeridos, ações, gestos, vozes, etc. -, conservando, muitas vezes, sua discrepância. Todos os demais criadores, porém, ao sugerir materiais com vistas à composição dramatúrgica e cênica, desempenham de alguma forma a função dramaturgia.

Decorre daí a dificuldade de se pretender uma dramaturgia textual e, consequentemente, uma encenação, semelhantes ao "organismo" perfeitamente estruturado da forma dramática convencional. É praticamente impossível encaixar na conformação canônica as contribuições de origens, aspectos e funções tão variados. Nesses casos, é necessário que o dramaturgo resista à tentação de operar com os estímulos da cena do mesmo modo com que opera uma dramaturgia particular, que resista a bloquear as leituras que se fazem de uma proposta nova por utilizar velhas lentes. Daí a importância de se discutir um pouco mais alguns sentidos abarcados pelo termo dramaturgia no teatro contemporâneo e verificar se contribuem para um alargamento de referências capaz de facilitar o trabalho dramatúrgico e sua leitura, seja por parte dos criadores, seja dos espectadores. É a isso que nos propomos com esse artigo. 


\section{DOIS SENTIDOS BÁSICOS}

Comecemos pela ampliação do conceito de dramaturgia. Da função de um autor único da peça teatral, que era o centro da encenação, ela passou a abarcar também o pensamento responsável pela passagem desse texto à cena, assim como a própria construção da cena por parte de toda a equipe, na ausência de um texto verbal preexistente. Daí que o professor Joseph Danan (2010) atribui dois sentidos básicos ao termo, entendendo que eles se ramificam e interagem permanentemente: o primeiro deles refere-se à função do autor dramático - é a noção mais convencional e, sob alguns aspectos, a mais limitada do termo -, desempenhada pelo dramaturgo. $\mathrm{O}$ segundo sentido refere-se à função do dramaturgista: aquele que não é o autor do texto dramático, mas, desempenha uma série de ações que envolvem a dramaturgia. É uma função atribuída a todos os responsáveis pela encenação.

Entendemos por dramaturgismo todo o trabalho de pesquisa, a fundamentação teórica da encenação, o acompanhamento dos ensaios, a escrita de textos críticos e de divulgação do espetáculo, bem como a eventual elaboração do texto verbal. Como se vê, ela comporta algumas atividades bastante comuns no processo colaborativo, daí a grande diferença entre as dramaturgias no sentido 1 e no sentido 2, lembrando que não são as personas do autor dramático e do dramaturgista que interessam, "mas a função nomeada dramaturgia que elas encarnam, assim como a carga teórica e prática desta noção" (DANAN, 2010, p. 06). Decorre daí uma noção de dramaturgia que se amplia da criação individual de uma peça de teatro (sentido 1) para o trabalho junto da cena assumido por todos (sentido 2). 
Segundo Danan, a equipe assume a função dramaturgia, tanto quanto o autor dramático.

Compreende-se hoje que o pensamento que norteia a construção de um espetáculo e que se constitui por seu intermédio é também dramaturgia. Os conceitos envolvidos, as ideias e a busca pela melhor forma de efetiválos na cena e relacionarem-se com o público pertencem a essa esfera imaterial. Tal reflexão encontra algumas de suas raízes nas proposições de Bernard Dort. Para ele, a dramaturgia, concebida como uma atividade que se distingue simultaneamente da escrita e da encenação é um estado de espírito, uma prática transversal (DORT, 1988).

Para que essa prática fosse efetivada, foi necessário que o texto deixasse de ocupar o centro gravitacional da encenação. Com o advento do encenador e a consequente compreensão da cena como lugar próprio de significação, não como tradução ou consecução de uma peça escrita, foi possível uma emancipação da representação em relação ao texto verbal preexistente. "Constata-se hoje uma emancipação progressiva dos elementos da representação e podemos verificar uma mudança em sua estrutura: a renúncia a uma unidade orgânica prescrita a priori e o reconhecimento do fato teatral como polifonia significante, aberta ao espectador". (DORT, 1998, p. 178).

Com isso, a representação não postula mais uma fusão ou uma união das artes - como pretendiam Richard Wagner ou E. Gordon Craig. Ocorre uma relativa independência dos elementos, a partir de sua equivalência: não só o texto é produtor de sentido, mas também o espaço e o cenário, a luz, os objetos e o figurino utilizados, a interpretação e tudo o mais. Há um discurso que percorre cada um deles, paralelamente, e que produz, segundo 
Dort, um combate pelo sentido, em que o espectador é, no final das contas, juiz.

No que se refere à emancipação da representação e, em consequência, do encenador, a professora Sílvia Fernandes afirma que:

O que distingue o encenador, novo artista da cena, de seus antecessores - o próprio dramaturgo, o ensaiador ou o primeiro ator da companhia - é o fato de que sua obra não pretende ser a simples disposição cênica de um conjunto, a marcação de entradas e saídas de elenco, a orientação de uma entonação de voz ou mesmo a rememoração e atualização de truques e convenções que persistem, através da história, como elementos de enformação do teatro. $\bigcirc$ encenador organiza o sentido do que se apresenta no palco, na medida em que não se limita mais a ordenar elementos, mas sistematiza concepções que dão um caráter ao projeto de encenação. Ele se transforma em "autor do espetáculo". (FERNANDES, 1996, p. 271).

Ao retomarmos a proposta de Danan em relação aos dois sentidos básicos da dramaturgia, verificamos que o sentido 1 estaria do lado do texto, enquanto o segundo, mais amplo, refere-se à passagem do texto à cena. No teatro contemporâneo, isso não implica mais numa ordem cronológica, pois a cena pode vir antes do texto verbal ou de um roteiro de ações. Não implica também numa função específica do dramaturgo ou do diretor, mas de todos, imbuídos de um "estado de espírito dramatúrgico" capaz de operar sobre as "virtualidades" (DORT, 1986, p. 8). O estado de espírito dramatúrgico vem substituir o "estado de espírito semiológico". Este, em vez de estruturar a representação como o confronto dos signos, procura considerá-la como um sistema de signos milimetricamente codificados, que direcionam a leitura a fim de controlar a construção do sentido por parte do espectador (DANAN, 2010, p. 35). A "reflexão sobre as virtualidades", ao contrário, permite que 
os signos se multipliquem, pois cada criador contribui de maneira singular para a narrativa geral do espetáculo - imbuído de um estado de espírito dramatúrgico.

Temos, com isso, que o trabalho dramatúrgico realizado em sala de ensaio no processo colaborativo é de responsabilidade de todos. Cada participante imagina, pesquisa e busca empreender suas ações a partir de um conjunto de signos específicos de sua área tendo em mente a comunicação com o público. Cada uma dessas áreas propõe um "texto" a ser decodificado pelo espectador, de modo específico ou integrado ao texto maior da encenação. Daí o entendimento de uma dramaturgia da luz, outra do cenário ou do ator e assim por diante. Ao ampliar a noção do termo, de modo a abarcar todas as esferas envolvidas na criação, pretende-se que cada criador assuma a responsabilidade comunicativa de suas proposições, sem delegar esse ônus tão somente ao dramaturgo e ao texto verbal.

DRAMATURGIA COMO TECIDO DE AÇÕES

Quando se fala em um texto particular de cada esfera criativa da encenação, a ser decodificado pelo espectador numa leitura própria, retomamos o sentido original da palavra texto: tecendo junto. Consequentemente, essa ideia de tecer junto implica na impossibilidade de uma representação cênica destituída de um texto. Temos, portanto, uma compreensão de dramaturgia como a arte de tramar os fios das ações no trabalho da encenação:

Numa representação, são ações (isto é, tudo que tem a ver com dramaturgia) não somente aquilo que é dito e feito, mas 
também os sons, as luzes e as mudanças no espaço. Num nível mais elevado de organização, as ações são os episódios da história ou as diferentes facetas de uma situação, os espaços de tempo entre dois clímax do espetáculo, entre duas mudanças no espaço (...). Os objetos usados na representação também são ações. Eles são transformados, adquirem diferentes significados e colorações emotivas distintas. Todas as relações, todas as interações entre as personagens e as luzes, os sons e o espaço, são ações. Tudo o que trabalha diretamente com a atenção do espectador em sua compreensão, suas emoções, sua cinestesia, é uma ação. (BARBA, 1995, p.69).

Na mesma página, Barba conclui que "as ações só são operantes quando estão entrelaçadas, quando se tornam textura, 'texto'". A dramaturgia tem, então, o seu sentido ampliado para além da autoria individual, sem que o dramaturgo perca a sua função. No nosso entender, por mais que o iluminador, o cenógrafo, o compositor tramem os fios de suas áreas, o dramaturgo pode ultrapassar a fronteira do texto escrito e assumir uma dramaturgia da cena. Ao observar sua escrita na conjunção com a luz, por exemplo, ou com a interpretação, com a trilha sonora, ele pode notar que determinado gesto ou marcação "dizem" mais sobre a situação do que algumas palavras e decidir por eliminá-las. Ou, ao contrário, pode avaliar que a transição entre uma cena e outra pede um texto a ser dito pelo ator (NICOLETE, 2005, p. 59). Há que se considerar, porém, as encenações destituídas de texto verbal. Nesses casos, cabe ao dramaturgo analisar as ações dos atores/personagens de acordo com um roteiro original ou, na ausência deste, de acordo com o que é elaborado ao longo das experimentações. Ele representa, de um certo modo, o espectador, na medida em que é capaz de identificar o que pode ou não ser compreendido 
por esse, o que está claro ou não, o que pode ser intensificado, problematizado e assim por diante.

Para Eugênio Barba, quando o artista considera o potencial comunicativo da obra, ele tem a possibilidade de planejar e encaminhar a relação com o espectador, orquestrar seus ritmos, induzir tensões sem pretender impor uma interpretação (BARBA, 1995, p. 70), pois há um fio que pertence ao nosso interlocutor externo e que pode ser trançado pelo dramaturgo no grande texto do espetáculo.

Tecer conjuntamente os fios de todas as instâncias criativas do espetáculo, levando em conta aquele que cabe ao espectador trançar, remete-nos ao princípio da polifonia (multiplicidade de sons), proposto por Mikhail Bakhtin (1997). Referindo-se aos romances de Dostoievski, Bakhtin constatou a coexistência de diferentes vozes, em detrimento da voz única do autor, mais comum na literatura da época: cada personagem assume uma trajetória e um tipo de conduta próprios e condizentes com o seu caráter. É como se tivessem existência independente do romancista, cuja função aparente seria registrar de modo organizado as diferentes trajetórias, trançálas. Um autor-tecelão, que dispõe do enredo, da trama, dos fiospersonagens, bem como do contexto na criação de sua arte. É possível se ter uma ideia da obra como um todo, do mesmo modo que se pode ver em cada personagem um fio único, independente da trama geral.

A polifonia é também uma marca da escrita teatral contemporânea, onde convivem as mais diversas "vozes", a sugerir diferentes significados, mas tecendo em conjunto o espetáculo, cuja totalidade supera a soma das partes, conforme visto anteriormente. Nesse contexto, o processo colaborativo é uma das dinâmicas que mais têm promovido uma tessitura polifônica da cena. Embora caiba ao diretor a busca de uma arregimentação 
das contribuições do grupo, é notável o quanto cada um dos fios pode apresentar cores, texturas, calibres, resistências, extensões diferentes. $\bigcirc$ tecido final do espetáculo, longe de propor uma unidade/uniformidade de aparência monológica, caracteriza-se justamente por sua dimensão heterogênea, pela sua polifonia/policromia ou pelo seu polimorfismo que se estendem à contribuição do espectador. Daí a imagem de colcha de retalhos associada a algumas encenações resultantes - algo próximo ao figurino do Arlequim, da commedia dell'arte, uma junção de vários tecidos -, ou seja, uma rapsódia.

\section{DRAMATURGIA COMO RAPSÓDIA}

Em sua obra O futuro do drama (2002), Jean-Pierre Sarrazac toma o vocábulo rapsódia - que em grego significa literalmente costurar - para representar o tipo de construção dramatúrgica feita da união de fragmentos de origens diversas. Em seguida, refere-se ao antigo rapsodo grego, autor e recitador de narrativas diversas, e propõe que o dramaturgo contemporâneo atue do mesmo modo que ele: unindo, costurando formas teatrais e extrateatrais numa composição única e tendo como aglutinador um pensamento que narra, mas também questiona - o ambiente, as circunstâncias, o estado das coisas. Da conjunção dessas duas ideias, Sarrazac define um modo de criação teatral ligado ao domínio épico, pois relacionado aos cantos e à narração homéricos, como também vinculado a procedimentos de escrita tais como a montagem, a hibridização, a colagem, a coralidade, característicos da cena contemporânea.

O ensaísta francês adota a rapsódia como o oposto de uma peça teatral de proporções equilibradas e estrutura definida - um organismo 
dotado de unidade em perfeito funcionamento. Sendo assim, o dramaturgo e todos aqueles que exercem a função dramaturgia em processos colaborativos, operam com a vivisseção, a desmontagem e o despedaçamento das formas antigas, buscando, no entanto, criar formas capazes de comunicar-se com o espectador de modo tão eficiente quanto o drama. Daí que esse retalhamento não se dá gratuitamente, apenas com a finalidade de descaracterizar a unidade peculiar à forma dramática. Trata-se de um transbordamento da própria forma e não o seu banimento:

Fazer fugir o sistema dramático (e não exauri-lo), é nisto que consiste o devir rapsódico do teatro. Neste jogo, ao qual se dedicam atualmente os diferentes modos poéticos, mesmo nos autores mais inventivos, é ainda o dramático, mesmo que muito limitado, que oferece esta dimensão de confrontação inter-humana que sempre esperamos do teatro, mesmo quando pressentimos o seu caráter decepcionante, incompleto, meio cego. (2002, p. 232).

Por isso a rapsódia, ainda que fundamentalmente épica em sua estrutura fragmentada, acolhe o lírico e o narrativo, mas também o dramático, aproveitando-se dos recursos que favoreçam tanto os objetivos internos da composição quanto a relação com o espectador, que na opinião de Sarrazac pode ser ainda mais intensificada.

Um segmento do teatro atual, e nele estão incluídas as dinâmicas coletivas, parece empreender uma busca por recuperar o sentido de proximidade com o espectador, a proximidade conquistada pelos rapsodos gregos, que costuravam narrativas (gênero épico) e interpretação de personagens (gêneros lírico e dramático) em uma mesma apresentação, a fim de comunicar diretamente os diversos gêneros discursivos com a comunidade de ouvintes. 
É importante reiterar o quanto a dramaturgia feita junto da cena solicita um autêntico trabalho rapsódico, de tecedura de ações. A sala de ensaio é um ateliê/oficina em que se processam as pesquisas áudio-vídeobibliográfica e empírica, os depoimentos e improvisos, as sugestões de cena e de texto verbal, assim como experimentos de luz, cenário, sonoridades e tantos outros elementos, constituindo todos eles dramaturgias próprias.

Como articular materiais tão diferentes, vindos de tantas fontes, com - objetivo de estabelecer uma dramaturgia da própria encenação? O importante é não perder de vista que cada um dos criadores responde pela função dramaturgia, por tecer as ações de sua competência, conferindo ao dramaturgo responsável a organização e a assinatura do todo. Mais do que selecionar uma porção de elementos e "costurá-los", cabe a ele, à luz dos objetivos pretendidos pelo grupo, buscar uma composição que seja mais que uma simples colagem das partes. Está aí um dos trabalhos mais difíceis e que requer uma experimentação contínua, pois conjuga até mesmo fatores subjetivos. Nesse tipo de dinâmica, desenvolve-se uma costura não só de materiais, como também de desejos, de expectativas e de frustrações, inclusive do espectador. Este último, só aos poucos e com a frequência constante a espetáculos não-convencionais, poderá desprender-se das formas dramáticas conhecidas - nas quais é especialista! - e entregar-se cada vez mais às novas propostas da cena contemporânea. 


\section{REFERÊNCIAS BIBLIOGRÁFICAS}

ABREU, Luís Alberto de. Processo colaborativo: relato e reflexões sobre uma experiência de criação. Cadernos da ELT, Santo André, v.1, n.0, p. 33-41, mar. 2003.

BAKHTIN, Mikhail. Problemas da poética de Dostoiévski. 2. ed. Tradução de Paulo Bezerra. Rio de Janeiro : Forense Universitária, 1997.

BARBA, Eugenio. Dramaturgia. In: BARBA, Eugenio, SAVARESE, Nicola. A arte secreta do ator: dicionário de antropologia teatral. Tradução de L. O. Burnier et al. São Paulo-Campinas: Hucitec - Unicamp, 1995. p. 68-73.

DANAN, Joseph. Qu'est-ce que la dramaturgie? Arles: Actes Sud-Papiers, 2010.

DORT, Bernard. La représentation émancipée : essais. Arles: Actes-sud, 1988.

FERNANDES, Sílvia. Memória e invenção: Gerald Thomas em cena. São Paulo: Perspectiva : FAPESP, 1996. P. 271.

NICOLETE, Adélia. Ateliês de dramaturgia: práticas de escrita a partir da integração artes visuais-texto-cena. 2013. Tese (Doutorado em Artes) Escola de Comunicações e Artes, Universidade de São Paulo, São Paulo.

Da cena ao texto : dramaturgia em processo colaborativo. 2005. Dissertação (Mestrado) - Escola de Comunicações e Artes, Universidade de São Paulo, São Paulo.

http://www.teses.usp.br/teses/disponiveis/27/27139/tde-28092009-

092332/pt-br.php

SARRAZAC, Jean-Pierre. O futuro do drama. Tradução de de A. M. Da Silva. Porto, Portugal: Campo das Letras, 2002.

SILVA, Antônio Carlos de Araújo. A gênese da vertigem: o processo de criação de O Paraíso Perdido. São Paulo: Perspectiva, 2011. 
ABSTRACT: It is intended, with this article, reflects on the meaning covered by the term dramaturgy in contemporary theater in order to support the search for new forms of verbal text and scene created in collective dynamics.

KEYWORDS: Dramaturgy; Theatre; Collaborative Process 